\section{RMD Open}

Rheumatic \&

Musculoskeletal Diseases

\title{
Cardiovascular drug treatment, statins and biopsy-confirmed giant cell arteritis: a population-based case-control study
}

Aleksandra Turkiewicz (D), ${ }^{1}$ Pavlos Stamatis (D), ${ }^{2,3}$ Aladdin J Mohammad (D) ${ }^{4,5}$

To cite: Turkiewicz A, Stamatis P, Mohammad AJ. Cardiovascular drug treatment, statins and biopsy-confirmed giant cell arteritis: a populationbased case-control study. RMD Open 2020;6:e001285. doi:10.1136/rmdopen-2020001285

- Supplemental material is published online only. To view please visit the journal online (http://dx.doi.org/10.1136/rmdo pen-2020-001285)

Received 23 April 2020 Revised 24 June 2020 Accepted 18 July 2020

Check for updates

\section{(C) Author(s) (or their} employer(s)) 2020. Re-use permitted under CC BY-NC. No commercial re-use. See rights and permissions. Published by BMJ.

${ }^{1}$ Clinical Sciences, Lund, Orthopedics, Lunds University Faculty of Medicine, Lund, Sweden

${ }^{2}$ Rheumatology, Lunds University Faculty of Medicine, Lund, Sweden

${ }^{3}$ Internal Medicine, Section of Rheumatology, Helsingborgs Lasarett, Helsingborg, Sweden ${ }^{4}$ Clinical Sciences Lund,

Rheumatology, Lunds University Faculty of Medicine, Lund, Sweden

${ }^{5}$ Department of Medicine, University of Cambridge, Cambridge, UK

Correspondence to Aladdin J Mohammad; aladdin. mohammad@med.lu.se

\section{ABSTRACT}

Objective To determine whether exposure to cardiovascular medications and statins is associated with increased risk of giant cell arteritis (GCA).

Design The population-based case-control study comprised a cohort of patients with biopsy-confirmed GCA linked to the Swedish Prescribed Drug Register to identify all exposure to drugs prior to diagnosis of GCA. Ten controls per GCA case, matched for age, sex and residential area, were included. Using corresponding Anatomical Therapeutic Chemical codes, ACE inhibitors, angiotensin II receptor blockers, beta-blocking agents, calcium antagonists, diuretics, statins and cardiac therapy drugs were investigated from July 1, 2005 to the diagnosis/index date. A conditional logistic regression model was fitted adjusted for income, education level and marital status. We repeated the analyses including only new drug users excluding those with any prescription during the year from July 1, 2005 to July 1, 2006.

Results 574 cases ( $29 \%$ men) of diagnosed GCA and 5740 controls ( $29 \%$ men) were included. The mean age at diagnosis is 75 years (SD 8). Of the GCA cases, $71 \%$ had at least one dispensation of a cardiovascular drug prior to the index date, compared to $74 \%$ of controls. The ORs for the association of target drug exposure with GCA were $<1$ for most drugs, but close to 1 in the analysis of new users. Statins were consistently associated with lower risk of GCA, OR 0.74 (95\% Cl 0.61 to 0.90 ).

Conclusion Statins may be associated with lower risk of incident biopsy-confirmed GCA. No association was evident for other studied drugs.

\section{INTRODUCTION}

Giant cell arteritis (GCA) is the most common primary vasculitis. It affects people older than 50 years and with higher incidence in women. ${ }^{1}$ It is characterised by inflammation of large vessels, especially the aorta and its main branches, with the most debilitating outcome being blindness due to involvement of arterial branches supplying the optic nerve. ${ }^{2}$ GCA most commonly affects people of northern Europe, with an annual incidence estimated from 14.1 to $22 / 100000$ inhabitants in individuals 50 years and older. ${ }^{3-5}$ The

\section{Key messages}

What is already known about this subject?

- Statins use is not associated with increased risk of giant cell arteritis (GCA).

- The use of angiotensin receptor blockers II may be associated with lower relapse rate and better relapse-free survival in GCA.

What does this study add?

- In this population-based case-control study, the use of statins was associated with reduced risk of developing GCA.

- Other cardiovascular drugs, such as diuretics and calcium antagonists, may be associated with lower risk of GCA, potentially after prolonged use of these drugs.

How might this impact on clinical practice?

- Larger prospective studies are needed to examine the effect of statins and other cardiovascular drugs on outcome GCA.

aetiology of GCA is unknown, but genetic and environmental factors have been suggested. The majority of patients with GCA carry one of the two closely related alleles HLA-DRB1*0401 and HLA-DRB1*0408. ${ }^{6}$ Smoking $^{7}$ and exposure to infection are among studied environmental factors. ${ }^{8} 9$ Few studies of the relationship of drug exposure with GCA have been published, and most were focused on the effects of drugs on disease outcome rather than on its incidence. Exposure to statins was reported to be not associated with increased risk of developing GCA in a French study enrolling 103 patients with GCA and 606 controls. ${ }^{10}$ In a large study including patients with biopsy-confirmed GCA, the use of angiotensin II receptor blockers in patients with GCA was associated with increased relapse-free survival, lower relapse rate and reduction in use of glucocorticosteroids. ${ }^{11}$ The intensity of immunostaining for angiotensin receptors in 
smooth muscle cells and inflammatory cells has been reported to be higher in the temporal arteries of patients with GCA compared to those with negative biopsies. ${ }^{12}$ In our retrospective study, use of beta-blockers was associated with a twofold occurrence of vision complications in patients with GCA, probably due to aggravation of optic nerve ischaemia. ${ }^{13}$

In this case-control study, we aimed to identify the potential role of cardiovascular drugs and statin therapy in the aetiology of GCA using data from a large population-based cohort of GCA patients and a validated national drug prescription database.

\section{METHODS}

\section{GCA cohort and controls}

In this case-control study, we used a population-based cohort of biopsy-confirmed incident cases of GCA diagnosed in the Skåne region, Sweden. All patients who underwent temporal artery biopsy from 1997 through 2016 were identified from a database of the Department of Pathology in Skåne, Sweden. ${ }^{3}$ For each GCA case, we selected 10 controls matched with respect to age ( \pm 1 year), sex and parish (an administrative unit smaller than town) of residency. The eligibility criteria for the controls were (1) to have visited a physician within the calendar year of GCA diagnosis of their respective case, (2) to be a resident of the Skåne region on December 31 of the year preceding the date of the physician visit, (3) older than 50 years at index date and (4) free of GCA at the time of GCA diagnosis of their respective case. In this way, the controls were sampled from the general population that produced the cases. The date of GCA diagnosis was used as index date for cases and their respective controls. Records of drug use were available from July 2005; in order to allow an exposure period of at least 6 months, the present study included incident GCA cases diagnosed from January 1, 2006 through October 31, 2015 and their respective controls. No other exclusion criteria were applied and no sample size estimation was done prior to the study, as we included all GCA cases from the geographical region. Ten controls per case were selected, to enable analyses in relevant smaller subgroups.

\section{Data sources}

Swedish Prescribed Drug Register

The Swedish Prescribed Drug Register (SPDR) contains information on drug use and expenditure for prescribed drugs for the entire Swedish population. ${ }^{14}$ The data in the SPDR include Anatomical Therapeutic Chemical (ATC) classification codes, dosage, number of packages, total number of daily doses prescribed, prescription cost, prescriber profession and the unique Swedish personal identification number. All prescription drugs, irrespective of reimbursement status, were included, while over-thecounter drugs not requiring prescription were not included. Pharmaceutical prescriptions after July 2005 are traceable for every person living in Sweden, and the unique personal identification number enabled linking of our GCA cohort with the SPDR. Information on dispensed cardiovascular drugs based on their ATC codes (table 1) were extracted for all cases and controls.

\section{Skåne Healthcare Register}

The Skåne Healthcare Register (SHR) is a mandatory register that includes information about all healthcare contacts made in the Skåne region (population 1.3 million) and covers all healthcare levels. ${ }^{15}$ Thus, contacts with both public and private clinics are recorded as long as the clinic is included in the public healthcare insurance system, as is the case for the majority of healthcare provision in the region. For each case and control, we extracted visit-specific data, including date, provider and level of care, from all visits after January 1, 1998. The SHR was used to identify eligible controls and to obtain information on comorbidities for those included in the study. Each healthcare contact generates up to eight diagnostic codes. The codes are registered according to the International Classification of Diseases version 10 (ICD-10).

Table 1 ATC codes of exposure drugs and number/percent of exposed persons in the analysis of any drug use or new drug use

\begin{tabular}{lllllll}
\hline & & \multicolumn{2}{l}{ Any drug use, $\mathbf{n}(\%)$} & & \multicolumn{2}{l}{ New drug use, $\mathbf{n}(\%)$} \\
\cline { 6 - 7 } Drug category & ATC code & GCA & Controls & & GCA & Controls \\
\hline ACE inhibitor & C09A & $130(23)$ & $1453(25)$ & & $39(14)$ & $201(14)$ \\
ARB & C09C & $106(18)$ & $1088(19)$ & & $20(7)$ & $83(6)$ \\
Beta-blocker & C07 & $205(36)$ & $2256(39)$ & & $45(16)$ & $203(14)$ \\
Calcium antagonist & C08 & $128(22)$ & $1421(25)$ & & $27(10)$ & $133(9)$ \\
Diuretic & C03 & $197(34)$ & $2341(41)$ & & $44(16)$ & $228(16)$ \\
Statin & C10AA & $169(29)$ & $2033(35)$ & & $32(11)$ & $224(16)$ \\
Cardiac therapy & C01 & $98(17)$ & $1162(20)$ & & $2(8)$ & $98(7)$ \\
Any exposure & All above & $368(67)$ & $4108(72)$ & & $104(37)$ & $544(39)$ \\
\hline
\end{tabular}

${ }^{*}$ Cardiac therapy includes cardiac glycosides (C01A), antiarrhythmics (C01B), vasodilators (C01D) and a small proportion of other (C01C or C01E). ARB, angiotensin receptor blocker; ATC, Anatomical Therapeutic Chemical; GCA, giant cell arteritis.

A single individual may have received drugs from more than one category. 


\section{Other registers}

We used the Population Register to retrieve information on age, sex, residential area and date of death of all included individuals. We extracted individual-level data on education and income from the Swedish Longitudinal Integrated Database for Health Insurance and Labor Market Studies held by Statistics Sweden (www.scb.se), the provider of official statistics in Sweden.

\section{Assessment of exposure and confounders}

The primary exposure of interest was the use of cardiovascular pharmaceuticals prior to GCA diagnosis. Drugs included ACE inhibitors (ACE-I), angiotensin II receptor blockers (ARBs), beta-blocking agents, diuretics, statins, calcium antagonists and cardiac therapy, mainly vasodilators and cardiac glycosides.

Two types of exposure were considered in this analysis: any drug use and new drug use. In the analysis of any drug use, we considered an individual exposed to a particular drug category if it had been dispensed at least once from July 1, 2005 to the index date. In the analysis of new drug use, we excluded cases and controls dispensed any of the drugs of interest from July 1, 2005 through June 30, 2006. We considered an individual exposed (ie, new user) if they had obtained the medication at least once in the period from July 1, 2006 through the index date.

Further, to evaluate potential dose-response effects, we categorised all subjects as either non-users, low-dose users or high-dose users of each drug. We classified this separately for each ATC code and strength/unit within each drug group. We classified doses above the median as high and below the median as low. Each person was classified as having high or low dose of a specific drug based on the most frequently dispensed dose, to avoid influence of dose-adaption phases. We further classified an individual as a high-dose user of a drug group when receiving a high dose of at least one drug from that group.

\section{Other covariates}

To characterise the clinical characteristics of the study population, we report assignment of the following diagnoses: ICD-10 group I (cardiovascular disease) and specifically myocardial infarction (I21), hypertension (I10), angina pectoris (I20), thrombosis (I08-I82, I74) or diabetes (E10-E14). Based on the data from the SHR, we defined an individual as having the disease if diagnosed at least once in primary, specialist or in-patient care before the initial drug exposure. In 2005, before exposure assessment, data of education was categorised as $\leq 9$ years, 10-12 years, 13-14 years and $\geq 15$ years; marital status was defined as married couples and registered domestic partners; and income as a continuous variable.

\section{Statistical analysis}

The descriptive data are presented as means and SD or frequencies and percentages. To quantify the association of drug exposure with subsequent development of GCA, a conditional logistic regression model was fitted for each drug category conditioned on matched sets. A crude model was fitted first and then a model adjusted for education level, marital status and income. To minimise the potential for bias by indication, we fitted the adjusted model only among persons with at least one drug from ATC group C (ie, drugs for cardiovascular system). As the association of drug use with the diagnosis of GCA may vary with duration of exposure, ${ }^{16}$ we fitted all models for any drug use and for new drug use. Estimates are presented as ORs with $95 \%$ CIs. Considering that we enrolled the controls from the atrisk set of the general population and that GCA is a rare disease, we suggest that the estimated ORs are good approximations of risk ratios. $^{17}$

The study is based on registry data that were linked through the use of a personal identifier. Ethics approval was provided by the Ethical Review Board in Lund (Dnr. 2010/517, 2013/720 and 2017/298).

\section{RESULTS}

\section{Characteristics of cases and controls}

We identified 574 individuals with incident biopsyconfirmed GCA and matched 5740 controls.

The medications of interest, their respective ATC codes and number of exposed cases and controls are shown in table 1 .

The mean age at diagnosis was 75 years (SD 8), $29 \%$ were men and almost $70 \%$ had at least one diagnosed cardiovascular disease (table 2). Almost half of the participants, 281 subjects with GCA and 1409 matched controls, were eligible for study of new drug use. These patients were younger at diagnosis, with a mean age of 71 (SD 8) years, and $54 \%$ had at least one diagnosed cardiovascular disease.

\section{Drug exposure}

The most commonly dispensed types of drugs were betablockers, diuretics, statins and ACE inhibitors used by $\sim 30 \%$ of all subjects (table 1 ). During the exposure assessment period, $47 \%$ of the cases and $55 \%$ of the controls used drug combinations, for example, diuretic plus ACE-I or ARB. The figures for new drug use were $20 \%$ of the cases and $21 \%$ of the controls.

In the analysis of any drug use, both crude and adjusted ORs were close to 1.0 for ARBs, and less than 1.0 for other analysed drugs, ranging from 0.74 to 0.85 and thus suggesting protective effects of these drugs. However, corresponding estimates for new use were close to 1.0, suggesting no relationship between drug exposure and incidence of GCA for most drugs (table 3).

The only association indicative of a protective effect in both any and new use was for statins, estimated ORs of 0.74 (95\% CI 0.61 to 0.90$)$ for any use and 0.71 (95\% CI 0.47 to1.07) for new use.

In the dose-response analysis, $\sim 25 \%$ of users were classified as receiving high drug doses. The ORs of subsequent development of GCA are summarised in table 4. Statins were the only drug group that exhibited clear dose-response patterns in analysis of new use (table 4). 
Table 2 Demographics of the study population

\begin{tabular}{|c|c|c|c|c|}
\hline & \multicolumn{2}{|l|}{ Any drug use } & \multicolumn{2}{|c|}{ New drug use } \\
\hline & GCA, $n=574$ & Controls, $n=5740$ & $G C A, n=281$ & Controls, $n=1409$ \\
\hline Age at index year in years, mean (SD) & $75.2(8.0)$ & $75.2(8.0)$ & $72.9(7.7)$ & $71.1(7.5)$ \\
\hline Sex, men, n (\%) & $164(29)$ & $1640(29)$ & $83(30)$ & $427(30)$ \\
\hline Annual income, ${ }^{\star}$ in 100000 SEK mean (SD) & $1.59(1.38)$ & $1.58(2.73)$ & $1.65(1.4)$ & $1.78(2.95)$ \\
\hline Married, ${ }^{*} \mathrm{n}(\%)$ & $415(73)$ & $4189(73)$ & $213(77)$ & $1109(79)$ \\
\hline \multicolumn{5}{|l|}{ Education, ${ }^{*} \mathrm{n}(\%)$} \\
\hline$\leq 9$ years & $230(41)$ & $2462(44)$ & $100(36)$ & $477(35)$ \\
\hline $10-12$ years & $231(41)$ & 2066 (37) & $117(42)$ & $527(38)$ \\
\hline $13-14$ years & $32(6)$ & $445(8)$ & $22(8)$ & $146(11)$ \\
\hline$\geq 15$ years & $70(12)$ & $657(12)$ & $38(14)$ & $226(16)$ \\
\hline Diagnosis from group I, n (\%) & $393(68)$ & $3614(63)$ & $180(64)$ & $727(52)$ \\
\hline Myocardial infarction, $\mathrm{n}(\%)$ & $29(5)$ & $303(5)$ & $10(4)$ & $45(3)$ \\
\hline Hypertension, n (\%) & $240(42)$ & $2065(36)$ & $97(35)$ & $315(22)$ \\
\hline Angina pectoris, $\mathrm{n}(\%)$ & $70(12)$ & $552(10)$ & $18(6)$ & $43(3)$ \\
\hline Thrombosis, n (\%) & $41(7)$ & $345(6)$ & $25(9)$ & $90(6)$ \\
\hline Diabetes, n (\%) & $55(10)$ & $648(11)$ & $21(7)$ & $114(8)$ \\
\hline Disorders of lipoprotein metabolism & $161(28)$ & $1735(30)$ & $48(17)$ & $276(20)$ \\
\hline
\end{tabular}

*For any drug use: $0.8 \%$ of the sample had missing data on income and marital status and $1.9 \%$ missing data on education; and For new drug use: $0.4 \%$ of the sample had income and marital status missing, $1.9 \%$ had missing data on education.

GCA, giant cell arteritis; SEK, Swedish kronor.

Table 3 ORs (95\% Cls) for the association of use of cardiovascular drugs with incidence of biopsy-confirmed giant cell arteritis

\begin{tabular}{|c|c|c|c|c|c|c|c|}
\hline \multirow[b]{3}{*}{ ACE inhibitor } & \multicolumn{3}{|c|}{ Adjusted for socioeconomic factors } & \multicolumn{4}{|c|}{$\begin{array}{l}\text { Subgroup with any treatment from ATC group C adjustec } \\
\text { for socioeconomic factors }\end{array}$} \\
\hline & Any drug use & \multicolumn{2}{|c|}{ New drug use } & \multicolumn{2}{|c|}{ Any drug use } & \multicolumn{2}{|c|}{ New drug use } \\
\hline & 0.85 (0.69 to 1.05$)$ & 1.01 & (0.69 to 1.50$)$ & 0.89 & (0.71 to 1.12$)$ & 1.10 & (0.65 to 1.86$)$ \\
\hline ARB & $0.97 \quad(0.77$ to 1.21$)$ & 1.40 & (0.83 to 2.35$)$ & 1.08 & (0.85 to 1.37$)$ & 1.33 & (0.71 to 2.49 ) \\
\hline Beta-blocker & 0.82 (0.68 to 0.99$)$ & 1.07 & (0.74 to 1.55$)$ & 0.86 & (0.69 to 1.06 ) & 1.05 & (0.64 to 1.72 ) \\
\hline Calcium antagonist & 0.85 (0.69 to 1.05$)$ & 1.09 & (0.69 to 1.72$)$ & 0.89 & (0.71 to 1.12$)$ & 0.98 & (0.55 to 1.73 ) \\
\hline Diuretic & 0.75 (0.62 to 0.91$)$ & 0.89 & (0.61 to 1.28$)$ & 0.77 & (0.62 to 0.96$)$ & 1.03 & (0.62 to 1.72$)$ \\
\hline Statin & 0.74 (0.61 to 0.90$)$ & 0.71 & (0.47 to 1.07$)$ & 0.78 & (0.62 to 0.96$)$ & 0.69 & (0.41 to 1.16$)$ \\
\hline Cardiac therapy & 0.79 (0.63 to 1.00$)$ & 1.10 & (0.66 to1.81) & 0.79 & (0.62 to 1.01 ) & 1.08 & (0.58 to 2.03 ) \\
\hline
\end{tabular}

Estimates from conditional logistic regression models.

ACE, angiotensin converting enzyme, ARB, angiotensin receptor blockers; ATC, Anatomical Therapeutic Chemical.

Most analysed drugs suggested a dose-response effect for any drug use, but not for new drug use.

In a sensitivity analysis, we adjusted our main analysis model for the presence of physician-diagnosed hypertension. The results remained essentially the same (online supplemental table 1).

\section{DISCUSSION}

The results of this large population-based cohort of patients with biopsy-confirmed GCA suggest that treatment with statins may lower the risk of GCA by $\sim 25 \%$. For other cardiovascular drugs, the interpretation is more challenging, due to therapies employing a combination of drug groups and differences in results of the analysis of any drug use versus new drug use. The analysis of new drug use suggests no relevant associations or potentially increased risk of GCA after initiation of ARBs. However, the analysis of any drug use suggests that the evaluated drugs, with the exception of ARBs, may be associated with 10-25\% lower risk for GCA when used over a longer time period. This may imply that the risk of GCA changes with duration of cardiovascular drug use and is reduced after several years.

Statin drugs are widely used in prevention of cardiovascular disease; however, the role of statins in GCA is not clear. ${ }^{18}$ Studies suggest that statins reduce levels of inflammatory markers, including $\mathrm{C}$ reactive protein, irrespective of the degree of lipid reduction. ${ }^{19}$ The antiinflammatory properties of statins are also evident in reducing the level of erythrocyte sedimentation rate in patients with GCA. ${ }^{20}$ Statin use during the course of GCA 
Table 4 ORs (95\% Cls) for the association between low-dose or high-dose exposure compared to no use of the drug

\begin{tabular}{|c|c|c|c|c|c|c|}
\hline \multirow[b]{2}{*}{ ACE inhibitor } & \multirow{2}{*}{$\begin{array}{l}\text { Dose, } \mathbf{n} \\
\text { Low, } 1143\end{array}$} & \multicolumn{2}{|c|}{ Any drug use } & \multirow{2}{*}{$\begin{array}{l}\text { Dose, } \mathbf{n} \\
\text { Low, } 204\end{array}$} & \multicolumn{2}{|c|}{ New drug use } \\
\hline & & 0.89 & (0.70 to 1.13 ) & & 1.05 & (0.69 to 1.60$)$ \\
\hline & High, 331 & 0.84 & (0.55 to 1.28$)$ & High, 36 & 0.81 & (0.30 to 2.19 ) \\
\hline \multirow[t]{2}{*}{ ARB } & Low, 842 & 0.98 & (0.76 to 1.27$)$ & Low, 78 & 1.61 & (0.91 to 2.86 ) \\
\hline & High, 266 & 0.79 & (0.49 to 1.27$)$ & High, 25 & 0.78 & (0.22 to 2.78$)$ \\
\hline \multirow[t]{2}{*}{ Beta-blocker } & Low, 1725 & 0.81 & (0.66 to 1.01$)$ & Low, 194 & 1.00 & (0.66 to 1.51$)$ \\
\hline & High, 541 & 0.73 & (0.52 to 1.03 ) & High, 54 & 1.35 & (0.69 to 2.65$)$ \\
\hline \multirow[t]{2}{*}{ Calcium antagonist } & Low, 1132 & 0.79 & (0.62 to 1.02$)$ & Low, 127 & 0.99 & (0.59 to 1.65$)$ \\
\hline & High, 319 & 0.86 & (0.57 to 1.30$)$ & High, 33 & 1.55 & (0.64 to 3.74$)$ \\
\hline \multirow[t]{2}{*}{ Diuretic } & Low, 1628 & 0.77 & (0.61 to 0.96 ) & Low, 204 & 0.78 & (0.51 to 1.20$)$ \\
\hline & High, 698 & 0.67 & (0.49 to 0.92$)$ & High, 68 & 1.23 & (0.66 to 2.28$)$ \\
\hline \multirow[t]{2}{*}{ Statin } & Low, 1272 & 0.67 & (0.53 to 0.86$)$ & Low, 127 & 0.75 & (0.44 to 1.29$)$ \\
\hline & High, 802 & 0.86 & (0.65 to 1.13 ) & High, 129 & 0.67 & (0.37 to 1.18$)$ \\
\hline \multirow[t]{2}{*}{ Cardiac therapy } & Low, 4193 & 0.76 & (0.62 to 0.93 ) & Low, 42 & 1.00 & (0.43 to 2.31$)$ \\
\hline & High, 247 & 0.65 & (0.39 to 1.09 ) & High, 15 & 0.83 & (0.18 to 3.81$)$ \\
\hline
\end{tabular}

ARB, angiotensin receptor blockers.

Estimates from conditional logistic regression models adjusted for income, education and marital status.

facilitates more rapid tapering of prednisolone dose. ${ }^{10}$ Furthermore, the anti-inflammatory effect of statins may be due to reduction of $\mathrm{CD} 4+\mathrm{CD} 28^{\text {null }} \mathrm{T}$ lymphocyte levels $^{21}$ and reduction of tumour necrosis factor-alpha or interlukin 6 levels. $^{22}$ In recent meta-analyses by Ungprasert $e t a l$, a specific pattern of metabolic features was associated with the development of GCA. ${ }^{23}$ Wadström et al have also recently suggested a negative association between the levels of cholesterol and triglycerides with the subsequent occurrence of GCA in a population-based cohort. ${ }^{24}$ Accordingly, the impact of statins on the occurrence of GCA in our study is most probably mediated through its anti-inflammatory effect rather than cholesterol-lowering effect.

Our results suggest that statin users exhibit consistently lower incidence of developing GCA compared with their controls, supported by analysis of both any drug use and new drug use, and the dose-response pattern. Although the dose-response pattern was not evident for any drug use, it was more apparent for new users.

However, potential strong bias by indication in statin users must be considered. ${ }^{25}$ Previous studies suggest a wide range of estimates of GCA in statin users, from an OR of 0.3 in patients at the Mayo Clinic and 0.7 in a subsample from Olmsted County, Minnesota, to 1.2 in a sample from France. ${ }^{10}{ }^{26}$ Our results with a relatively large sample provide narrower CIs, suggesting a moderate $\sim 25 \%$ reduction in risk. The question remains of the potential advantages of statin therapy as add-on to the standard of care of patients with GCA, considering its anti-inflammatory effects as well as its role in prevention of cardiovascular events. ${ }^{102327}$

Angiotensin II is a vasoconstrictive peptide with proinflammatory activity including activation of human peripheral monocytes leading to the release of tumour necrosis factor alfa and other adhesion molecules. ${ }^{28}$ In a study enrolling 10 patients with biopsy-confirmed GCA and 10 controls with no GCA diagnosis, the angiotensin-1 receptor staining in biopsy tissue was more intense in subjects with GCA. ${ }^{12}$ In line with these findings, an observational study of 106 patients with GCA reported ARB therapy to be associated with lower relapse rate and extended disease-free survival. All patients were treated according to standard of care with glucocorticosteroids (GCs) and methotrexate, as indicated. ${ }^{11}$ The possible source of these benefits may be the anti-inflammatory effect of ARBs. In our study, exposure to ARBs was not associated with lower risk of GCA, and the analysis of new drug use suggested a potentially increased risk of GCA after initiation of ARB therapy (OR 1.40 (CI 0.83 to 2.35)). A possible explanation is that our study assessed $\mathrm{ARB}$ as a risk factor for GCA, while the cited studies evaluated the effect of ARBs in persons diagnosed with GCA. In addition, we cannot exclude unmeasured confounding from smoking or unrecognised risk factors.

There is little information in the literature with respect to use of other cardiovascular drugs and risk of GCA. Other drug groups included in our study, ACE inhibitors, beta-blockers, diuretics, calcium antagonists and cardiac therapies, primarily vasodilators and cardiac glycosides, were associated with lower risk of GCA in the analysis of any drug use. This protective effect was not confirmed in analysis of new drug use, in which all estimates were closer to 1. Data from a previous study analysing the risk of cardiovascular events following GCA reported those with GCA to be slightly more frequently prescribed antiplatelet agents, beta-blockers, statins and nitrates than those without ${ }^{29}$ However, this study included individuals free of serious cardiovascular disease at the time of diagnosis, and only $30 \%$ of GCA cases and $27 \%$ of controls were diagnosed with hypertension. These results are not directly comparable to ours, as $>60 \%$ of those included in 
our sample had pre-existing cardiovascular disease diagnosed by a physician.

Our study has some important limitations. In the entire cohort, $47 \%$ of the cases and $55 \%$ of the controls used more than one drug or a combination of ACE inhibitors or ARBs and diuretics during the exposure period. To disentangle the specific effects of each drug is challenging but the situation reflects clinical reality. This rate was lower when studying new drug use, $20 \%$ of cases and $21 \%$ of controls, but still considerable. Thus, the similar estimates obtained for different drug groups may be explained in part by overlap in use or by bias-byindication due to underlying cardiovascular disease. We consider the analysis of new drug use less biased, but it included fewer patients and thus led to less conclusive results, a typical problem in studying rare diseases such as GCA. We were not able to adjust the analysis for smoking due to lack of data. Another limitation of this study is that the analysis was restricted to patients with biopsy-verified GCA which may reduce the generalisability of our results, perhaps making them not applicable to patients with negative temporal artery biopsy or those with isolated large vessel vasculitis. Although many analyses were performed within this study, we attempted not to interpret the results based on statistical significance testing, but rather on the values included in the CIs, and most importantly, the consistency of the results between analyses. ${ }^{30}$

There are also important strengths. We included a large sample of persons with validated incident cases of biopsyconfirmed GCA. The controls were sampled from the underlying at-risk population that produced the cases. We adjusted for several potential confounders, including socioeconomic factors, and the cases and controls were matched with respect to parish of residence, a small geographic unit, to adjust for access to care. The assessment of drug use was based on a national register covering all dispensed medications and we were able to perform a dose-response analysis to strengthen the existence of a potentially true effect. Further, our study sample included all identified GCA cases in the region without specific selection criteria and thus reflects clinical reality.

\section{CONCLUSIONS}

Use of statins may be associated with $\sim 25 \%$ lower risk of GCA. Other cardiovascular drugs, such as diuretics and calcium antagonists, may be associated with lower risk of GCA, but this effect was observed only in the analysis of any drug use and thus may take affect only with prolonged use.

Contributors All authors were involved in drafting the article or revising it critically for important intellectual content, and all authors approved the final version to be published. Study conception and design, acquisition of data and data interpretation: AT, PS, AJM. Statistical analysis: AT. Obtaining of funding: AJM.

Funding This study was supported by grants from the Swedish Research Council (Vetenskapsrådet: 2019-01655) and Faculty of Medicine, Lund University (ALF-medel). Competing interests None declared.

Patient consent for publication Not required.
Ethics approval The study is based on registry data that were linked through use of a personal identifier. Ethics approval was provided by the Ethical Review Board in Lund (Dnr. 2010/517, 2013/720 and 2017/298).

Provenance and peer review Not commissioned; externally peer reviewed.

Data availability statement Data are protected by the confidentiality laws in Sweden and cannot be shared. The statistical programmes are available on reasonable request. All data relevant to the study are included in the article or uploaded as supplementary information. Please contact corresponding author.

Supplemental material This content has been supplied by the author(s). It has not been vetted by BMJ Publishing Group Limited (BMJ) and may not have been peer-reviewed. Any opinions or recommendations discussed are solely those of the author(s) and are not endorsed by BMJ. BMJ disclaims all liability and responsibility arising from any reliance placed on the content. Where the content includes any translated material, BMJ does not warrant the accuracy and reliability of the translations (including but not limited to local regulations, clinical guidelines, terminology, drug names and drug dosages), and is not responsible for any error and/or omissions arising from translation and adaptation or otherwise.

Open access This is an open access article distributed in accordance with the Creative Commons Attribution Non Commercial (CC BY-NC 4.0) license, which permits others to distribute, remix, adapt, build upon this work non-commercially, and license their derivative works on different terms, provided the original work is properly cited, appropriate credit is given, any changes made indicated, and the use is non-commercial. See: http://creativecommons.org/licenses/by-nc/4.0/.

\section{ORCID iDs}

Aleksandra Turkiewicz http://orcid.org/0000-0003-1460-2275

Pavlos Stamatis http://orcid.org/0000-0003-1760-0734

Aladdin J Mohammad http://orcid.org/0000-0002-7169-6936

\section{REFERENCES}

1 Dejaco C, Duftner C, Buttgereit F, et al. The spectrum of giant cell arteritis and polymyalgia rheumatica: revisiting the concept of the disease. Rheumatology 2017;56:506-15.

2 Gonzalez-Gay MA, Barros S, Lopez-Diaz MJ, et al. Giant cell arteritis: disease patterns of clinical presentation in a series of 240 patients. Medicine 2005;84:269-76.

3 Mohammad AJ, Nilsson JA, Jacobsson LT, et al. Incidence and mortality rates of biopsy-proven giant cell arteritis in Southern Sweden. Ann Rheum Dis 2015;74:993-7.

4 Brekke LK, Diamantopoulos AP, Fevang BT, et al. Incidence of giant cell arteritis in Western Norway 1972-2012: a retrospective cohort study. Arthritis Res Ther 2017;19:278.

5 Petursdottir V, Johansson H, Nordborg E, et al. The epidemiology of biopsy-positive giant cell arteritis: special reference to cyclic fluctuations. Rheumatology 1999;38:1208-12.

6 Weyand CM, Hicok KC, Hunder GG, et al. The HLA-DRB1 locus as a genetic component in giant cell arteritis. Mapping of a disease-linked sequence motif to the antigen binding site of the HLA-DR molecule. $J$ Clin Invest 1992;90:2355-61.

7 Brennan DN, Ungprasert P, Warrington KJ, et al. Smoking as a risk factor for giant cell arteritis: a systematic review and meta-analysis. Semin Arthritis Rheum 2018;48:529-37.

8 Rhee RL, Grayson PC, Merkel PA, et al. Infections and the risk of incident giant cell arteritis: a population-based, case-control study. Ann Rheum Dis 2017;76:1031-5.

9 Gilden D, White T, Khmeleva N, et al. VZV in biopsy-positive and negative giant cell arteritis: analysis of $100+$ temporal arteries. Neurol Neuroimmunol Neuroinflamm 2016;3:e216.

10 Pugnet G, Sailler L, Bourrel R, et al. Is statin exposure associated with occurrence or better outcome in giant cell arteritis? Results from a French population-based study. J Rheumatol 2015;42:316-22.

11 Alba MA, Garcia-Martinez A, Prieto-Gonzalez S, et al. Treatment with angiotensin II receptor blockers is associated with prolonged relapse-free survival, lower relapse rate, and corticosteroid-sparing effect in patients with giant cell arteritis. Semin Arthritis Rheum 2014;43:772-7.

12 Dimitrijevic I, Malmsjo M, Andersson C, et al. Increased angiotensin II type 1 receptor expression in temporal arteries from patients with giant cell arteritis. Ophthalmology 2009;116:990-6.

13 Saleh M, Turesson C, Englund M, et al. Visual complications in patients with biopsy-proven giant cell arteritis: a population-based study. $J$ Rheumatol 2016;43:1559-65.

14 Wettermark B, Hammar N, Fored CM, et al. The new Swedish Prescribed Drug Register: opportunities for pharmacoepidemiological 
research and experience from the first six months. Pharmacoepidemiol Drug Saf 2007;16:726-35

15 Lofvendahl S, Schelin MEC, Joud A. The value of the Skane Healthcare Register: prospectively collected individual-level data for population-based studies. Scand J Public Health 2020;48:56-63.

16 Hernan MA, Alonso A, Logan R, et al. Observational studies analyzed like randomized experiments: an application to postmenopausal hormone therapy and coronary heart disease. Epidemiology 2008;19:766-79.

17 Gail MH, Altman DG, Cadarette SM, et al. Design choices for observational studies of the effect of exposure on disease incidence. BMJ Open 2019;9:e031031.

18 Monti S, Agueda AF, Luqmani RA, et al. Systematic literature review informing the 2018 update of the EULAR recommendation for the management of large vessel vasculitis: focus on giant cell arteritis. RMD Open 2019;5:e001003.

19 Kent SM, Flaherty PJ, Coyle LC, et al. Effect of atorvastatin and pravastatin on serum C-reactive protein. Am Heart J 2003;145:e8.

20 Hegg R, Lee AG, Tagg NT, et al. Statin or nonsteroidal anti-inflammatory drug use is associated with lower erythrocyte sedimentation rate in patients with giant cell arteritis. J Neuroophthalmol 2011;31:135-8.

21 Brugaletta S, Biasucci LM, Pinnelli M, et al. Novel anti-inflammatory effect of statins: reduction of CD4+CD28null T lymphocyte frequency in patients with unstable angina. Heart 2006;92:249-50.
22 Devaraj S, Chan E, Jialal I. Direct demonstration of an antiinflammatory effect of simvastatin in subjects with the metabolic syndrome. J Clin Endocrinol Metab 2006;91:4489-96.

23 Ungprasert P, Upala S, Sanguankeo A, et al. Patients with giant cell arteritis have a lower prevalence of diabetes mellitus: a systematic review and meta-analysis. Modern Rheumatol Japan Rheumatism Association 2016;26:410-4.

24 Wadstrom K, Jacobsson L, Mohammad AJ, et al. Negative associations for fasting blood glucose, cholesterol and triglyceride levels with the development of giant cell arteritis. Rheumatology 2020

25 Glynn RJ, Schneeweiss S, Wang PS, et al. Selective prescribing led to overestimation of the benefits of lipid-lowering drugs. J Clin Epidemiol 2006;59:819-28.

26 Schmidt J, Kermani TA, Muratore F, et al. Statin use in giant cell arteritis: a retrospective study. J Rheumatol 2013;40:910-5.

27 Ray JG, Mamdani MM, Geerts WH. Giant cell arteritis and cardiovascular disease in older adults. Heart 2005;91:324-8.

28 Hahn AW, Jonas U, Buhler FR, et al. Activation of human peripheral monocytes by angiotensin II. FEBS Lett 1994;347:178-80.

29 Tomasson G, Peloquin C, Mohammad A, et al. Risk for cardiovascula disease early and late after a diagnosis of giant-cell arteritis: a cohort study. Ann Intern Med 2014;160:73-80.

30 Wasserstein RL, Schirm AL, Lazar NA. Moving to a world beyond "p<0.05". Am Stat 2019;73:1-19. 